\title{
Analysis of usage of geographic information systems for the participants of tourist travels
}

\author{
Witold Chmielarz, University of Warsaw, witold@chmielarz.eu \\ Oskar Szumski, University of Warsaw, oskar.szumski@uw.edu.pl
}

\begin{abstract}
The main objective of this article is to analyze the usage of geographic information systems (GIS) with regard to tourism. The study has been limited to a select group of individual users. The article presents the characteristics of the systems' users and their opinions regarding the possibilities and the extent of the use of GIS during individual trips, package tours, and tourist travels. The authors have presented a discussion of the obtained results and have drawn conclusions from the current research
\end{abstract}

Keywords: geographic information systems, mobile devices, tourism.

\section{Introduction}

The main aim of this paper is to analyze the usage of Geographic Information Systems (GIS) from the point of view of people planning and taking trips. GIS supporting such services are still regarded as a new and dynamically developing phenomenon, which is both heterogeneous and extremely diversified. For this reason, the evaluation and development strategies of GIS remain uncertain, and the ultimate size and scope of their application are very difficult to predict. This article is aimed at examining the situations where GIS are used by people leaving their place of residence in order to take organized individual or business trips. It should be noted that at present, the popularity and universal character of such services is further promoted by the fast development of information technology.

The most popular definitions of GIS are as follows:

- ...geographic information systems are information systems with the database which includes observations on the spatially located features, activities and events ... (Dueker, 1979),

- ... a set of efficient tools used to gather, store, freely access, process and display spatial data concerning the real world... (Burrough, 1986),

- ... spatial information system - the system used for obtaining, processing and presenting data which contain spatial information and relevant description regarding objects. If the data are used to depict geographical environment - we deal with a geographic information system..(Gaździcki, 1990; Obermeyer \& Pinto, 2008),

- ...computer information systems used to enter, collect, process and present spatial data, whose basic function is to support the decision-making processes... (Kraak, \& Ormeling, 1998; Harmon \& Anderson, 2003), 
- ...geographical information system is an integrated network of hardware, software, geographical data, research methods and specialists, where all its elements operate in an institutional context... (Longley, Goodchild, Maguire, \& Rhind, 2015).

The definitions cited above are consistent with regard to the statement that GIS are used to store, collect, process, and display the data that is geographically located in the real world. However, more recently we tend to focus more on the technology aspect of the phenomenon. The above said context, owing to the readily available access to the Internet and GIS, enables individual, non-professional users to participate in the benefits provided by GIS. The group of GIS users has expanded beyond a select group of specialists, and now includes individuals who use the systems for their own needs. These individuals organize their leisure time and shopping, in addition to arranging the rental of real property, equipment, and automobiles.

In view of the ongoing technological developments (e.g. increasing popularity of smartphones, tablets, and relevant mobile applications), notwithstanding numerous publications concerning GIS, the area still requires an in-depth examination. The situation in the market is changing rapidly. At present there are around 1.8 million people employed in the mobile applications market within the EU, and in 2015 the revenues from the sector were $€ 39.6$ billion. It is estimated that by 2018, the number of employees will rise to 4.8 billion and the revenues will reach approximately $€ 63$ billion (Interia Mobtech, 2014). More and more frequently, the offer of mobile applications includes GIS designed not only to suit the requirements of institutional clients, but also to cater for the needs of individual users. These GIS support professional spatial applications as well as non-professional use, such as organizing our own daily activities.

Taking the above mentioned factors into consideration, the authors would like to propose a new definition for the needs of the present research: GIS are a conglomerate of traditional (object, point) and modern (network) information systems used to collect, integrate, process, and interpret heterogeneous, multi-dimensional information and spatial knowledge, located in an economic and legal environment of the area where they are implemented.

The practice and research (Goodchild, Longley, Maguire, \& Rhind, 2006; Gotlib, Iwaniak, \& Olszewski, 2008) to date regarding the applications of GIS focus mainly on the following areas:

- public institutions, e.g. operating in the field of crisis management, flood control systems (Instytut Meteorologii i Gospodarki Wodnej, 2015; Regionalny Zarząd Gospodarki Wodnej w Krakowie, 2015a; Regionalny Zarząd Gospodarki Wodnej w Krakowie, 2015b), national parks management, geographic data of public administration units (Urząd m. st.. Warszawy, 2012; WarszawskaStarowka.pl, 2015), health care (Wikipedia, 2015), official statistics (Portal Geostatystyczny, 2015), military units,

- private companies, including activities pertaining to: geomarketing (ArcGIS, 2015; ESRI, 2015), company asset management (Aplikom, 2015), telecommunications (GEOPORTAL 2, 2015), property market (Targeo, 2015), and logistics (Caliper, 2015),

- individual users, including location (Google, 2015), vehicle navigation (AutoMapa, 2015), tourism (Avdimiotis, Mavrodontis, Dermetzopoulos, \& Riavoglou, 2006; Boers \& Cottrell, 2007; Brown \& Weber, 2013), interactive geo-information maps (Urząd Miejski w Bytowie, 2015). 
Taking individual users of the GIS into account, the most popular applications are the systems used for tourism purposes, which are directly connected with other functionalities listed above. Therefore, the authors have undertaken research aimed at analyzing the use of the relevant applications among individual users. The findings presented in the article are a summary report of the first stage of the research conducted among the selected group of users in Poland in 2015.

\section{The assumptions of the research methodology}

Due to limited and fragmentary research examining GIS applications from the point of view of individual clients in both Polish and foreign literature (Carver, 1991; Bahaire \& Elliott-White 1999; Poslad et al. 2015), this study has been based on the authors' own approach, consisting of the following five steps:

- creation of the questionnaire analysis of a selected group of GIS users,

- pilot run of a study among nine, randomly selected users and the substantive (adding, modifying, expanding and eliminating questions included in the survey) and technical (stylistics, users' perception) verification of the survey,

- placing the Internet version of the survey on servers of the Faculty of Management of the University of Warsaw and a subsequent feasibility test,

- circulating the survey among the users, the analysis, and discussion of the findings,

- drawing conclusions with regard to the present state and development trends of GIS in tourism based on users' opinions.

The article presents the results of the research. The study was concluded by the end of November 2015. The study sample was not accidental, as the selection of the respondents was purposeful, random sampling. The participants were students of part-time and full-time B.A., B.Sc., M.A., and post-graduate studies. Additional participants were members of the administrative and academic staff of selected universities in Warsaw (University of Warsaw and Vistula University). The questionnaire surveys were circulated electronically, and the response rate exceeded $80 \%$. Students are a group which is open to all kinds of innovations, in particular applications for private use and entertainment.

The limitation with regard to the selected sample was, among others, a considerable number of participants with smartphones, tablets and mobile phones characterized by lower quality, but with longer period of use, and, undoubtedly, limited access to company devices (for more arguments see: (Chmielarz, 2015; Chmielarz \& Luczak, 2015)). In total, 349 people filled out the questionnaire, 329 respondents fully completed the survey and 17 questionnaires were completed only partially or incorrectly. Women accounted for $59.88 \%$ of the respondents, while men were $40.12 \%$ of the respondents. The largest age group, over $50 \%$ of participants, were 19 and 20 year olds. Over $35 \%$ of the respondents were 21 or 22 years old, which is the age group typical of students in the first years of B.A. and B.Sc. studies. Additionally, more than $11 \%$ of participants were aged 23-30, the age which is characteristic for the students of a full- or part-time MA program. Only $3 \%$ of respondents were over 31 years of age, a group consisting of BA or postgraduate students, as well as members of administrative and academic staff. The survey participants were $61.7 \%$ of traditional students, $36.17 \%$ of working students, and $2.13 \%$ of university employees. Over $50 \%$ of the respondents stated that they come from a city with over 
500,000 inhabitants, nearly $8 \%$ from cities with $100-500$ thousand residents, almost $9 \%$ from cities with 50-100 thousand inhabitants, more than 14\% from towns with 10-50 thousand residents, close to $6 \%$ from towns with up to 10,000 inhabitants, and $13.1 \%$ came from rural areas. The simplicity of the questionnaire did not bring about any distortions during its completion, and few (17) respondents provided additional comments.

\section{Analysis of the findings and discussion of the results}

Respondents provided answers to 25 questions, which were diversified in terms of the undertaken activities and the degree of familiarity with GIS.

The questionnaire consisted of three substantive sections: functional, technical, and system environment. Demographics of the respondents were also collected. The first section contained three parts concerning the use of GIS: before departure, during departure, and after departure. Each part had slightly different, detailed content.

The first part (before departure) included:

- specifying the scope of the systems' applications relating to individual, organized and business trips of the respondents, their friends and relatives, when they used GIS (the location of the object, the object's surroundings, getting to the object, view of the object),

- the influence of the anonymous opinions and the opinions of friends found on the Internet on the decisions related to taking trips (no influence, little influence, medium impact, are very important, do not know),

- the importance of GIS visualizations for the users' decisions to take a trip and their choice of accommodation (no influence, little influence, medium impact, are very important, do not know),

- the impact of GIS on the decisions relating to future accommodation (no influence, little influence, medium impact, are very important, do not know).

The second part (at the time of departure) had questions concerning:

- the decision to send information relating to the users' geolocation (do not send, send little, rarely send, send a lot, do not know),

- the possibility of using GIS during travelling and trip planning (useless, little use, on average suitable, useful to a high degree, do not know),

- the impact of GIS on the decisions relating to changing of the location (no impact, no impact, low impact, medium, large, do not know),

- the importance of GIS for planning additional excursions during tourist trips (no, a little, on average, much, do not know),

- scope of use of GIS during the change of accommodation (no, a little, on average, much, do not know).

The third part (after departure) included:

- frequency place of memories, photos, and videos from the trip (never, rarely, on average, 
often, do not know),

- subsequent virtual visits via GIS to places known from previous trips (yes/no),

- the intention to use GIS once again for tourist purposes, based on previous experience (yes/no).

The technical section contains only three questions:

- the type of a device providing access to GIS applications (smartphone, tablet, laptop, other device),

- tagging travel destinations (never, rarely, on average, often, do not know),

- sending information about geolocation (never, rarely, on average, often, do not know).

The system environment section consist of:

- the possibility of use or potential use of other systems from the level of GIS (ticket reservation systems, hotel reservation systems, ticket reservation system for mass events and individual (theaters, cinemas, etc.), and similar systems accessed by the respondent,

- other GIS used by respondent (for the purchase, rental properties, investment decisions, decisions about trips to places of training, conferences, other).

Analysis of the findings and discussion of the results are presented below.

The first set of questions concerned the scope of GIS applications in three cases: individual trips, package tours, and business trips.

Over $92 \%$ of respondents gave positive answers to the question on the use of GIS during individual trips, 51\% - during package tours, and less than $47 \%$ during business trips. The respondents were asked about the main purposes of using the systems before the trip, which included route planning, the location of the facilities, their surroundings, and the appearance of the premises. The results of the study are presented in Figure 1. 


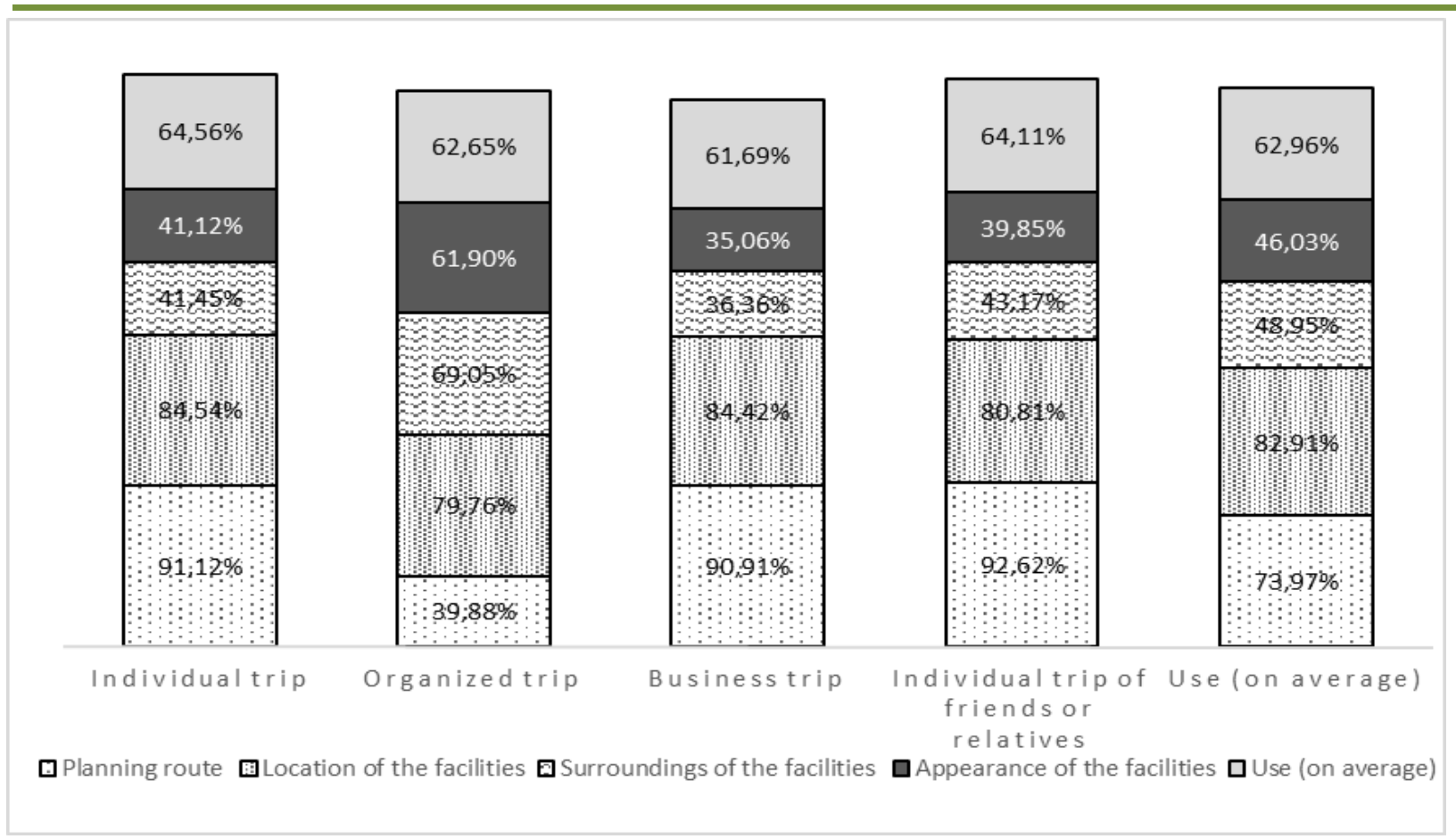

Figure 1. The use of GIS

Before taking individual trips, GIS users analyzed access routes to facilities (over 91\%) and location of the premises (85\%). The remaining two purposes in the ranking were placed below the average (65\%). The discrepancy between the smallest and the largest values amounts to 50 percentage points. Before embarking on package tours, we note that the interest in planning routes is much lower than in the previous case and amounts to only $39.88 \%$, which is understandable considering the fact that the transport service is provided by the travel agency. The location and the surroundings of the objects rank above the average 63\%, and the appearance of the objects is slightly below this level. The difference between the highest and lowest values amounts to nearly 40 percentage points. In the case of business trips, over $90 \%$ of travelers focus on checking access routes to facilities, and they are less interested in the appearance of the premises (35.06\%). The spread of the opinions is the greatest, and it equals about $55 \%$. On average, the location of the premises seems to be of utmost importance (82.91\%), with planning a route being important as well (73.97\%). Checking the surroundings and the appearance of facilities rank below the average of $62.96 \%$. If we take the average values pertaining to the use of the system into consideration, the use of GIS presents the lowest span between the highest and the smallest values and amounts to $28 \%$.

The respondents were asked similar questions about the experiences of their families, relatives, and friends. These responses were less positive than in the previous stage, $82.37 \%$ of the responses being positive. The answers provided by survey participants clearly indicate that access routes to facilities $(91.62 \%)$ and the location of the facilities $(80.81 \%)$ are the main purposes of using GIS. The two remaining reasons reach average values around $40 \%, 20 \%$ below the average score. The difference between the extreme values in this case is 53 percentage points. 
The next factor examined by the authors was the impact of the opinions, both anonymous recommendations and the views of their friends, published on the Internet (forums, travel agency websites, travel blogs, etc.) on the decisions concerning the trips. It turned out that people who use this form of information are influenced by the opinions of friends (this view is shared by $41 \%$ of the sample), and anonymous opinions are markedly less important (about half of the previous score). Anonymous opinions have moderate influence on the decisions taken by travellers, as indicated by $48.63 \%$ of the users. Only 3-4\% of the group declare that they are not influenced by the opinions at all. The differences are presented in Figure 2.

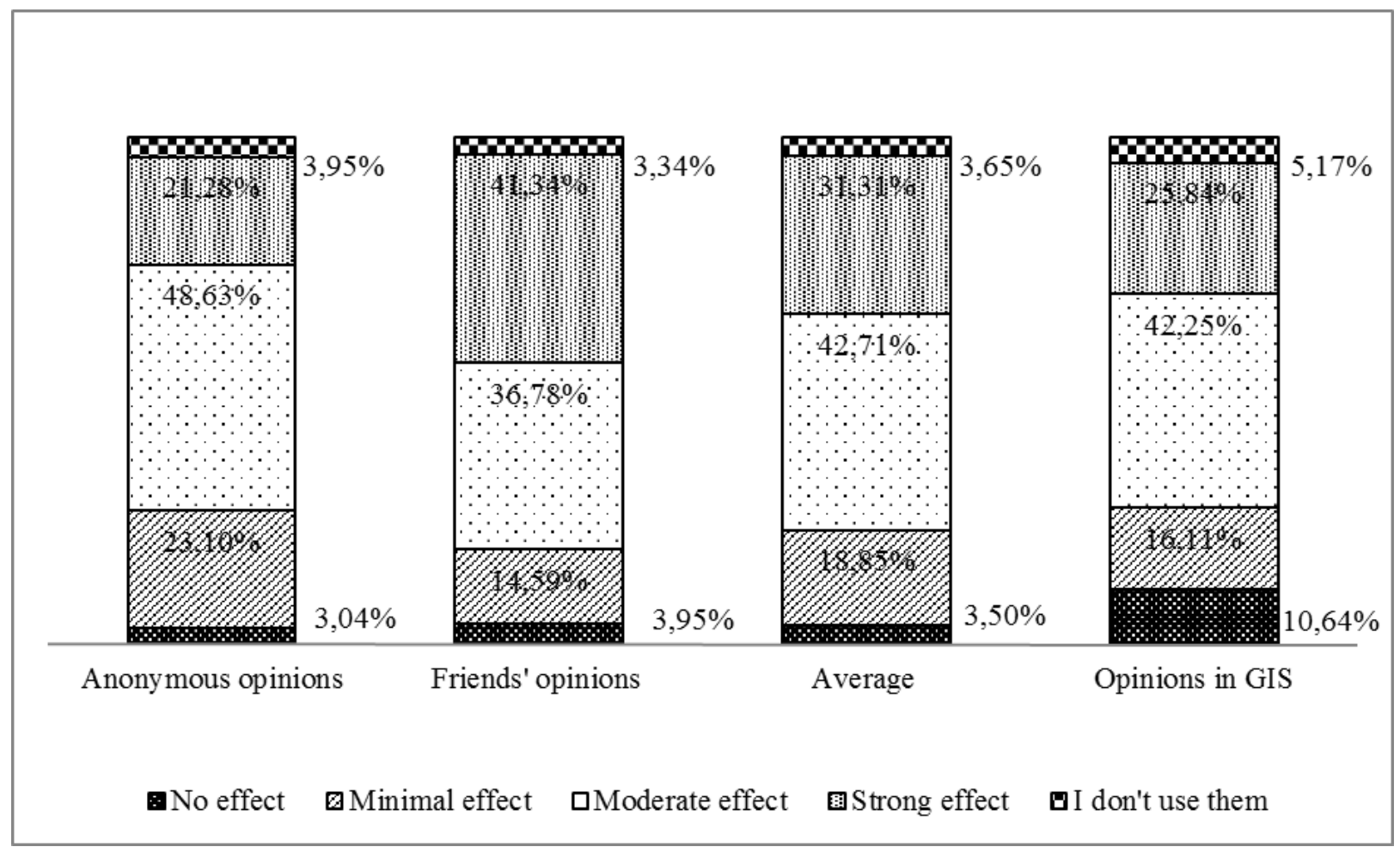

Figure 2. The influence of anonymous opinions and the opinions of friends posted in the Internet on the decision concerning a choice of a given location vs. the effect of GIS

Interesting results are obtained when we compare the above opinions with the impact of GIS on the decisions relating to the choice of accommodation. Generally, it emerges that both average opinions encountered on the Internet, as well as the information and visualizations obtained from GIS, influence $60 \%$ of the respondents' decisions to a small or moderate degree. We may notice considerable differences only in the case of statistics with regard to the lack of impact - the difference of over 7 percentage points in plus in the case of GIS and of considerable impact - the difference amounting to $5.5 \%$ in favor of the opinions published in the Internet. Hence, it appears that the opinions of friends, relatives and family published in the Internet media other than GIS are of major importance for the decisions made by the travelers.

The research data indicate that the impact of GIS on the choice of accommodation seems to produce better results. Here, almost $29 \%$ of respondents answered that they are frequently influenced by GIS, and almost $30 \%$ declare that they are moderately affected by GIS (ref.: Figure 3). 


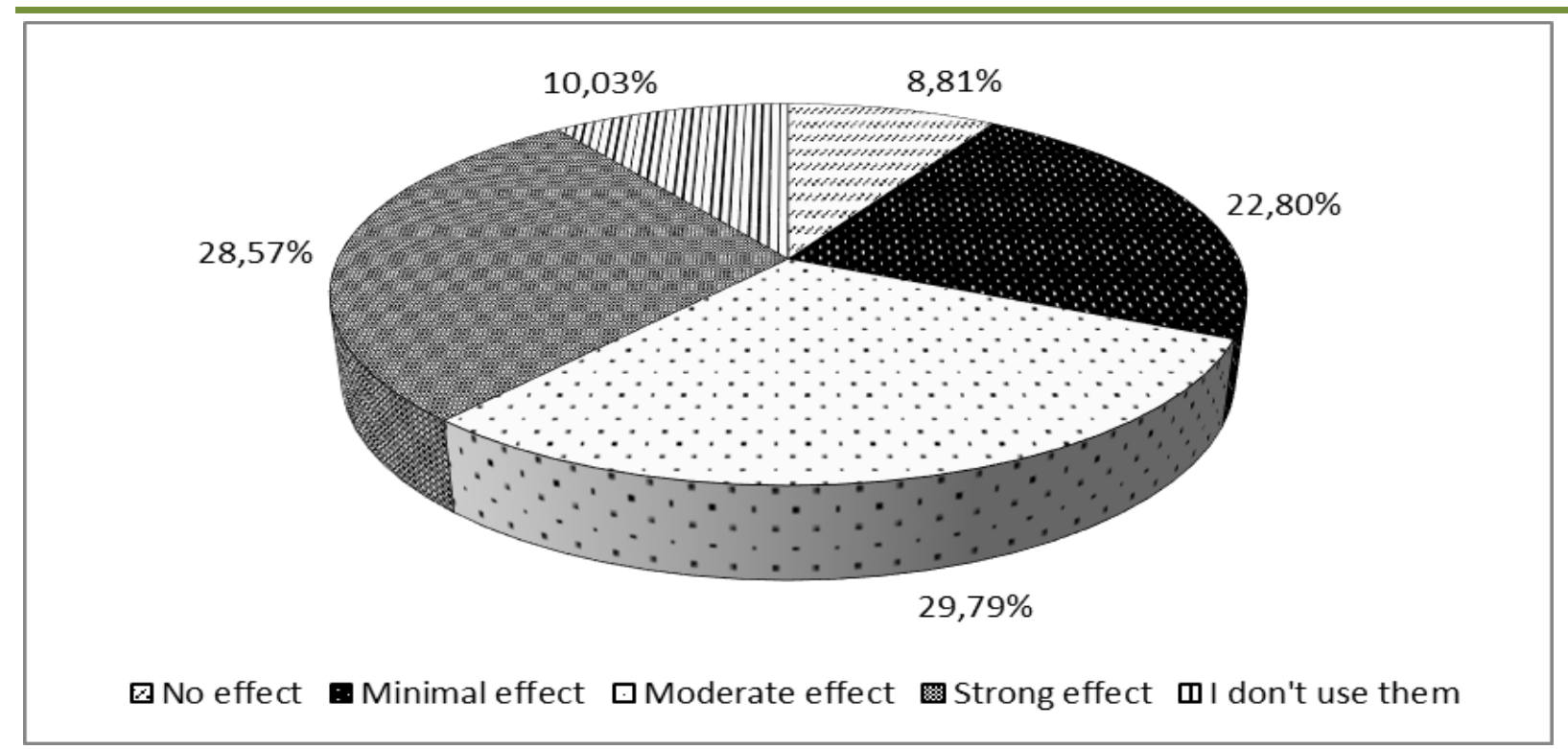

Figure 3. The scope of GIS use when making a decision on a choice of accommodation (e.g. hotel, hostel, apartment, campsite)

In the case of moving from place to place while travelling, about $40 \%$ of respondents are willing to use GIS, and over $40 \%$ use GIS to a moderate degree. Less than $20 \%$ declare that they seldom use GIS, or that they do not use the systems at all. The data pertaining to planning routes while travelling indicate very similar tendencies. The greatest difference is visible in the case of a response ...I seldom use GIS..., where such an answer was provided by over 5\% more users than in the case of moving to another location. The issue connected with selecting overnight accommodation is different. In this case over $54 \%$ of users use the GIS frequently or moderately. Unfortunately, the number of people who do not use the systems at all increases to $22 \%$. The answers 'quite a lot' or 'moderately' constitute, on average, over $69 \%$ of all answers. The findings of the study are presented in Figure 4. 


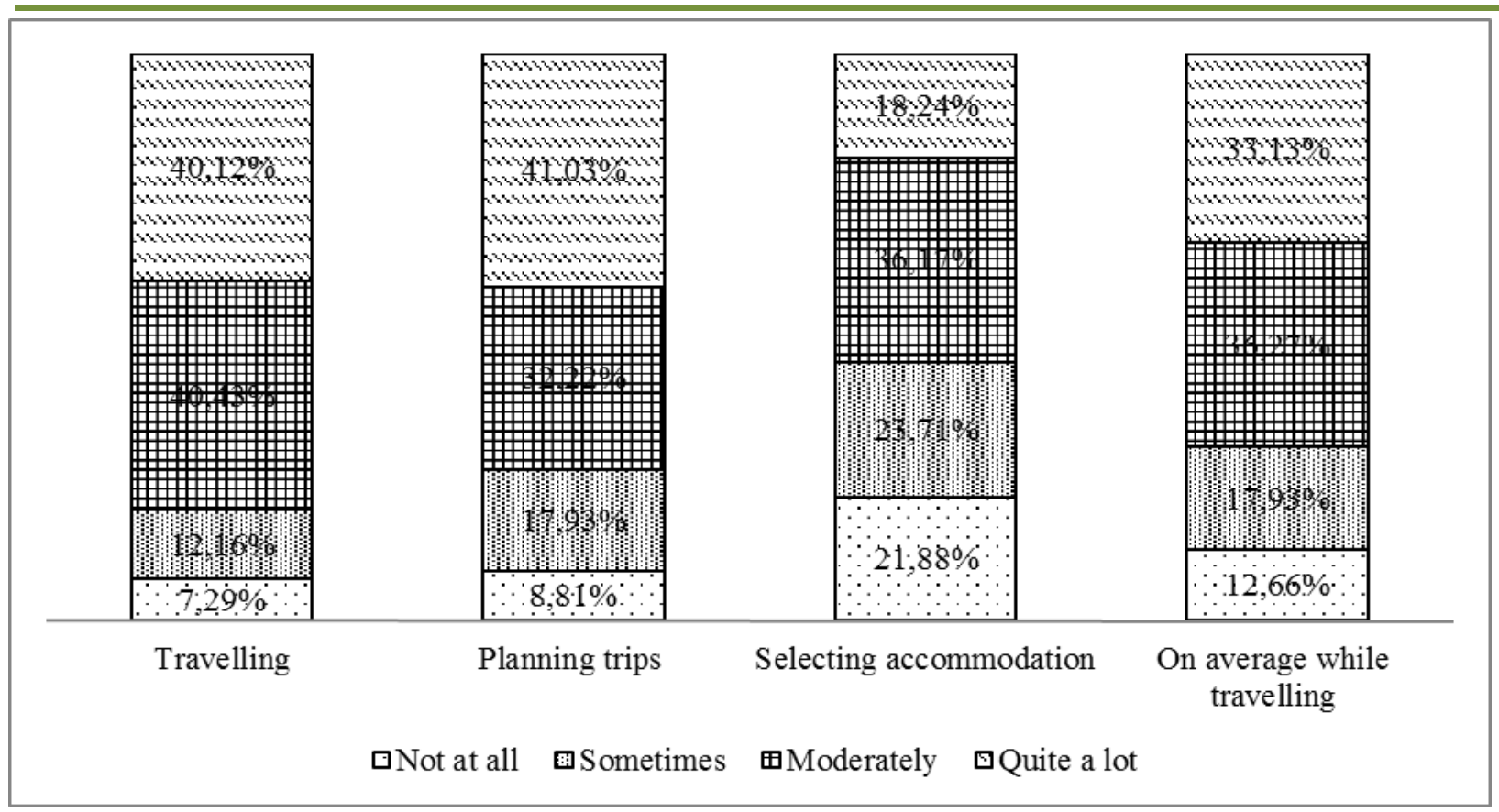

Figure 4. The use of GIS during a trip when moving from the start location to other locations, when planning a trip or selecting accommodation

The next question was devised to summarize the considerations on the usefulness of GIS during travelling. Over $50 \%$ of respondents answered that GIS are useful to a considerable degree. They turned out to be moderately useful for $32 \%$ of users. Only $4 \%$ claimed that for them GIS are not useful at all.

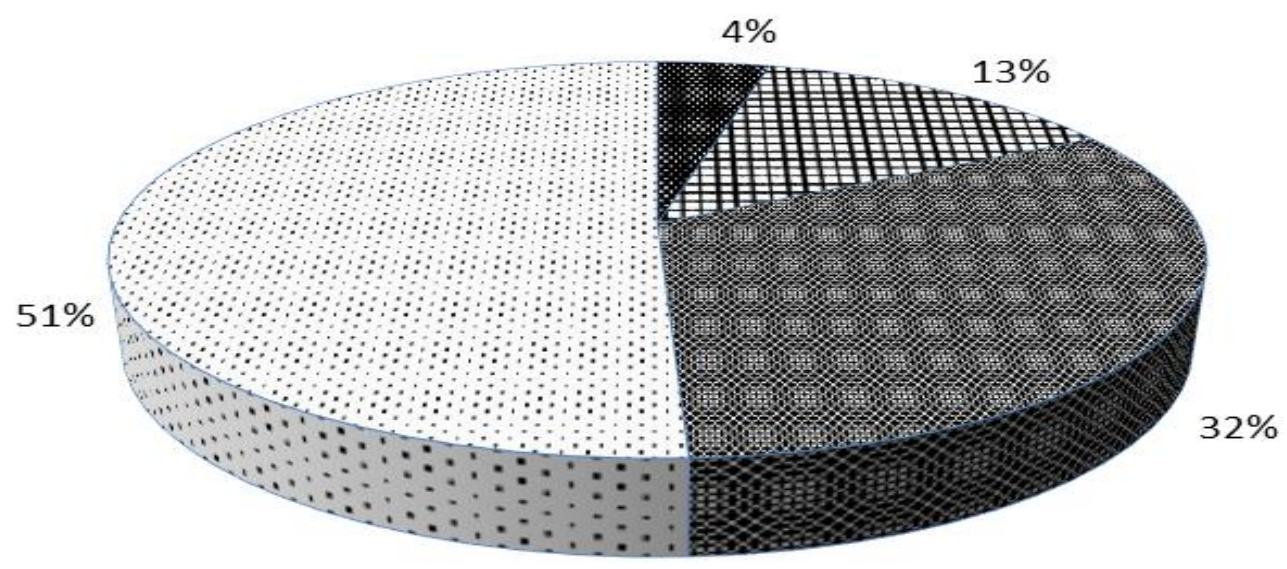

Not useful at all $\boxplus$ Not particularly useful Quite useful $\square$ Very useful

Figure 5. The degree of usefulness of GIS technology during trips 
The next set of questions queries analyzed the more technical aspects of the examined issue. The question pertaining to the devices which provide access to GIS was especially important due to the considerations discussed in the first part of the paper. Over $56 \%$ of the respondents use mainly smartphones, $16 \%$ use tablets, $23 \%$ use laptops, and only 5\% utilize other equipment (ref.: Fig.6). The current research confirms the visible growing popularity of the devices such as smartphones and tablets which are increasingly more compact and more user-friendly, especially while travelling. As the survey participants had the possibility to indicate more than one device in the survey, the tendencies seem even stronger with93\% of survey participants indicating that they use smartphones, while $27 \%$ use tablets. Due to the fact that the size of laptops is becoming increasingly smaller (to such a degree that it does not significantly differ from the size of a tablet) and the functionalities of the laptop are much wider, laptops take the second position in both rankings, and the share of users who access GIS using this equipment amounts to $38 \%$. The selection of the sample probably contributes to such a high percentage of smartphone users in the group as the percentage of smartphone or tablet holders among students is much higher than among representatives of other groups in the population.

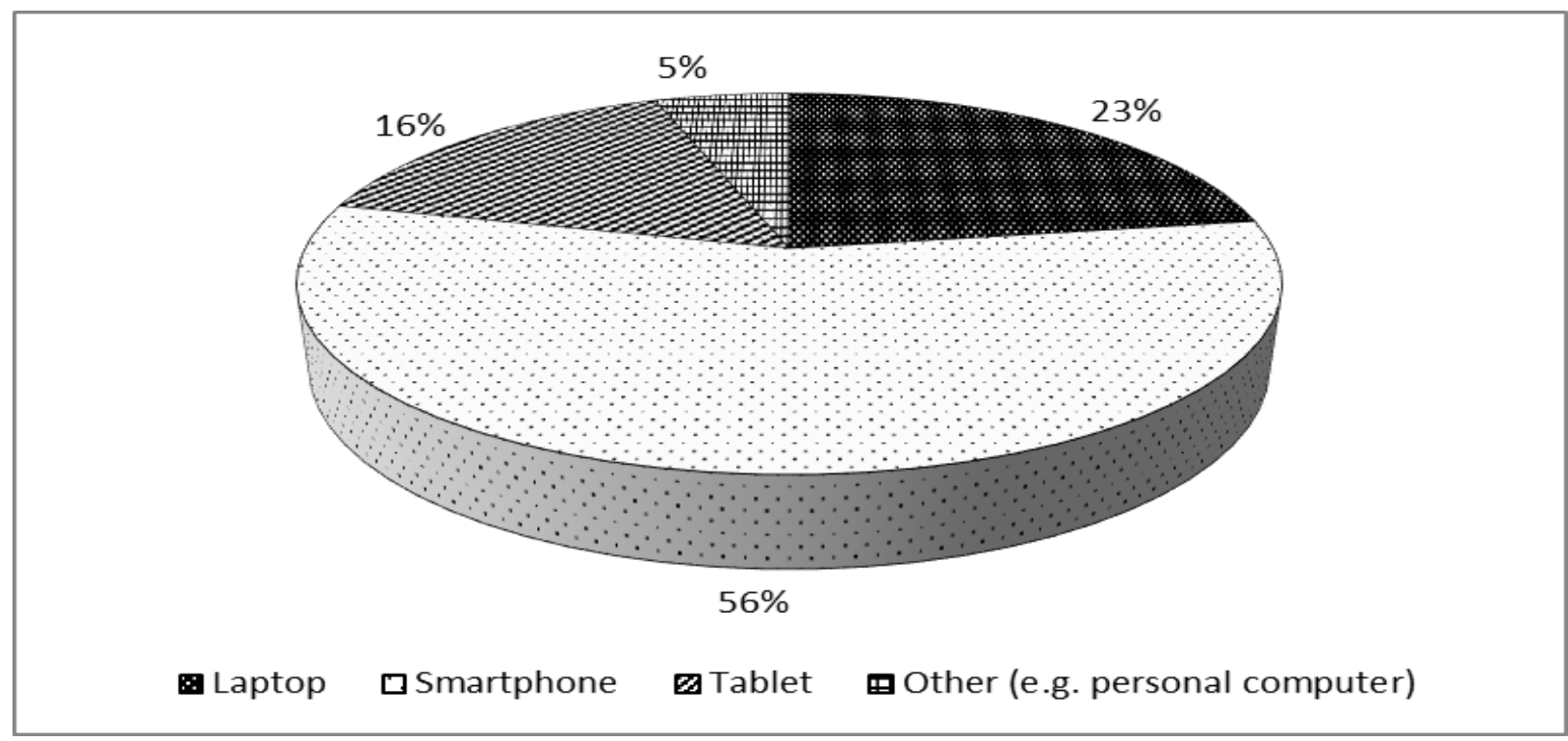

Figure 6. Devices with GIS access used by respondents during trips

The question concerning the deliberate sending of the information about one's location was of a more technical nature. The answers clearly indicate that respondents are not interested in this functionality, with $76 \%$ of the participants indicating that they do not send, or seldom send, such information, and only $5 \%$ of the respondents indicating that they send it regularly (Figure 7). 


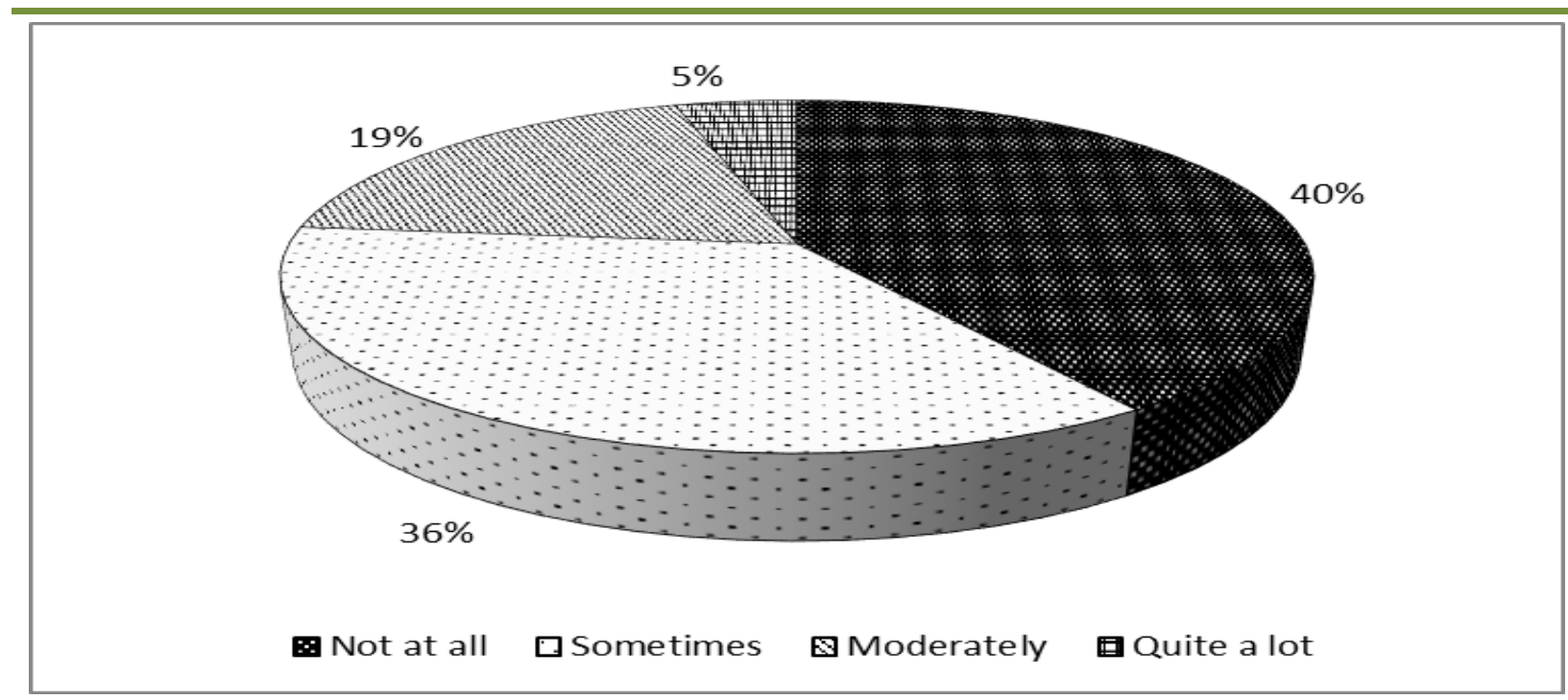

Figure 7. Intentional sending of information concerning the user's geolocation during the trip

We may note that the users are just as reluctant to use the functionality of tagging their locations during travelling. Only $2 \%$ of participants provided positive responses to those questions, and only $10 \%$ seldom use this functionality. $69 \%$ of the sample never use the tagging option.

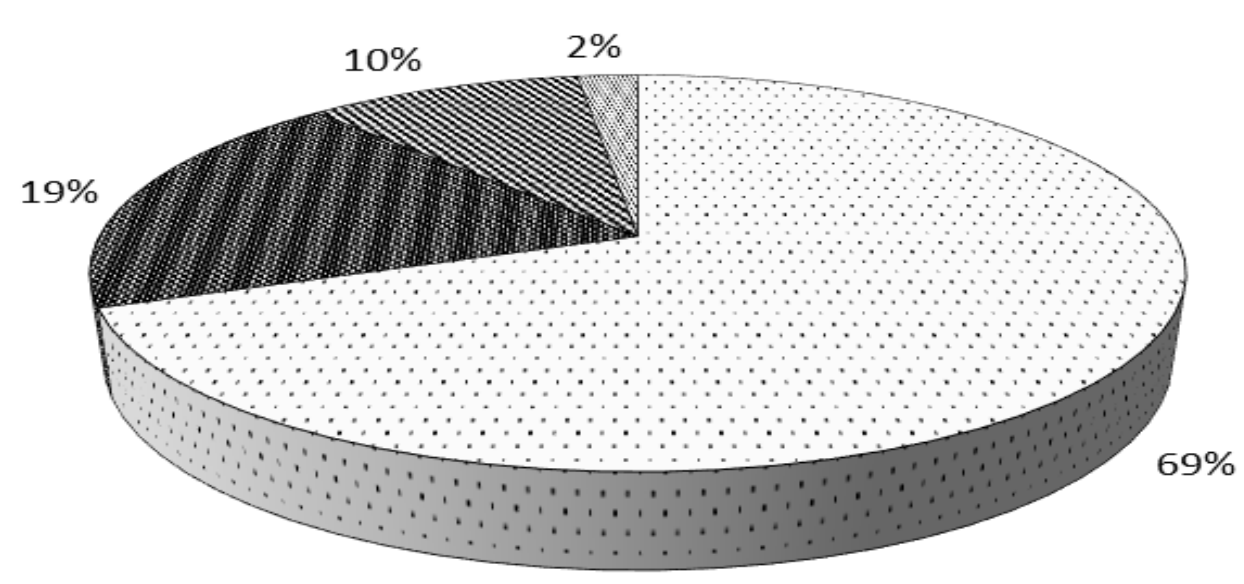

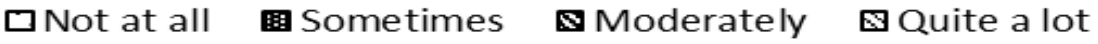

Figure 8. Tagging places visited during the trip in GIS

Generally, the possibility of placing photos or videos documenting trips in social media is not approached enthusiastically. The options ... Not at all... and ...Sometimes... are indicated by the $65 \%$ of the sample. Only $11 \%$ of the respondents state that they post quite a lot of photographs and videos, which is contrary to previous verbal indications. Based on the comments preceding the survey, the percentage should be much higher (ref.: Figure 9). And, interestingly, the users, at least over $58 \%$ share of the sample, do not visit via GIS the places which they recently visited. 


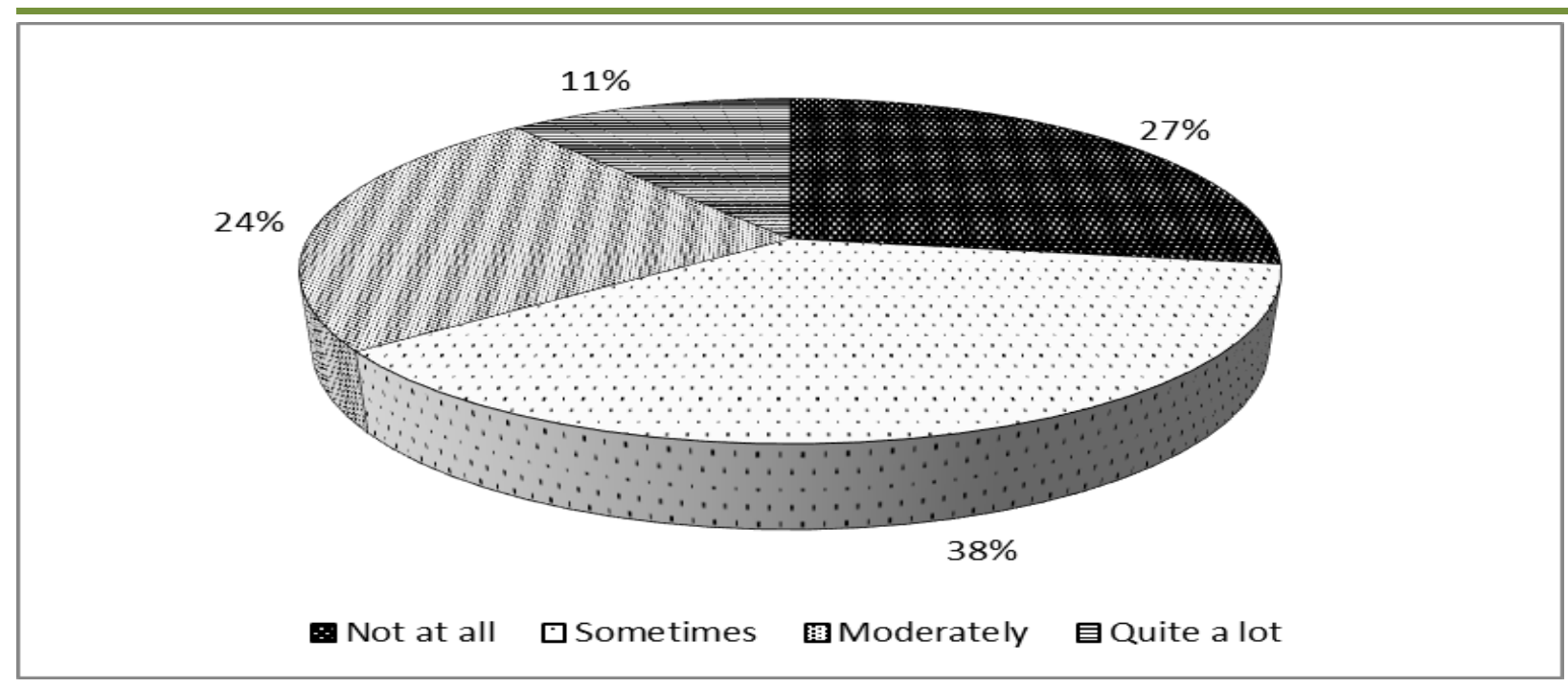

Figure 9. Posting photos or videos documenting trips in social media (e.g. Facebook)

On the other hand, despite the clear lack of enthusiasm to use tagging, confirmation of geolocation, or posting photos or videos documenting travels in social media, over $80 \%$ of the respondents claim that using GIS during their trip encourages them to use this tool again. The analysis of the data with regard to the indication of the software the respondents currently use and the one they would like to use to access GIS produces interesting results. The travel and hotel booking systems seem to be used to a satisfactory degree. The ticket booking service for mass events and cultural events seems to be used to an insufficient degree. It is estimated at about $11 \%$, and tourist information systems seem to be used to excess in the opinions of a similar group of survey participants (Figure 10).

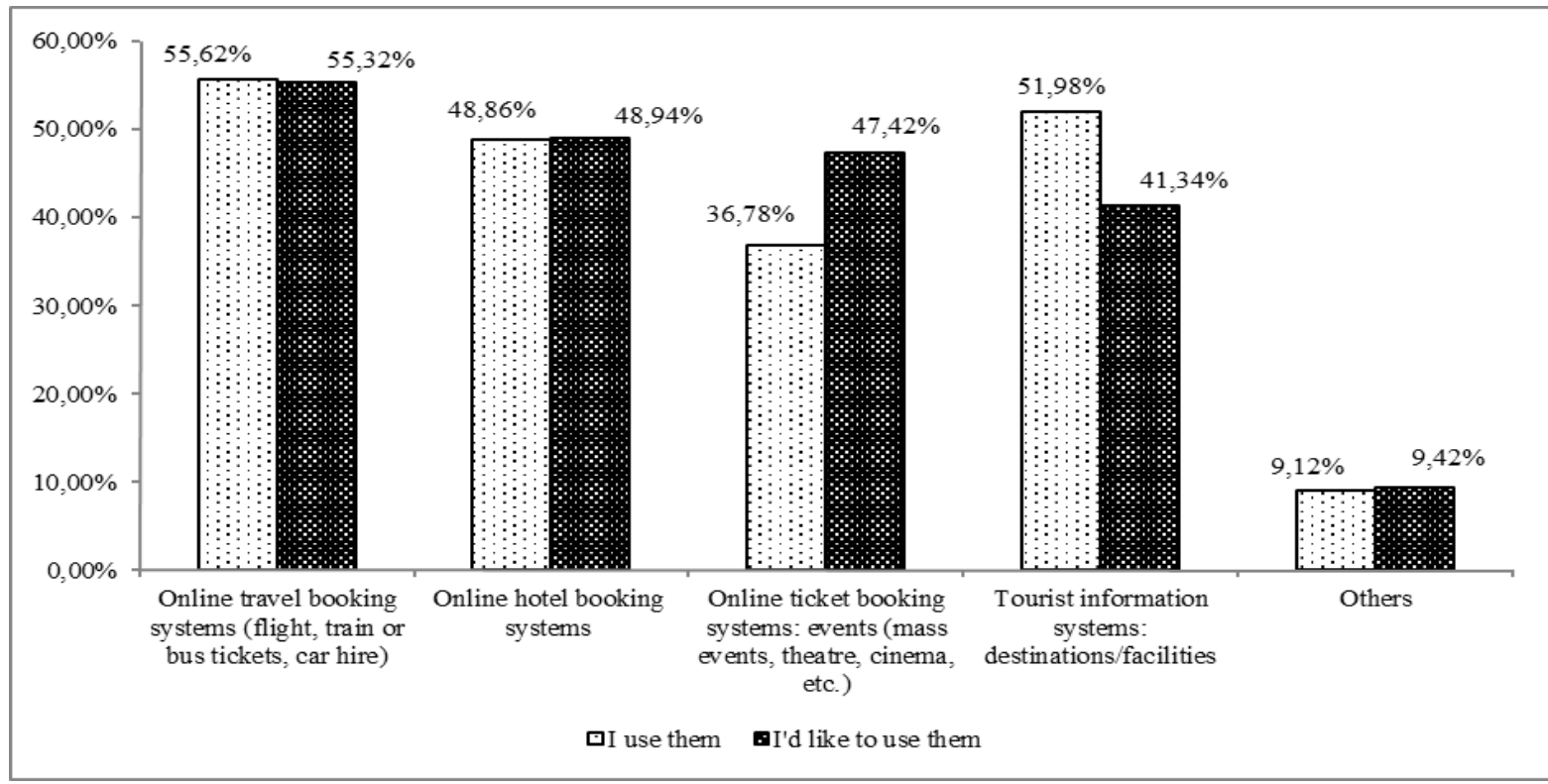

Figure 10. The types of GIS-related systems used and considered for potential use 
In the present study, the authors have conducted preliminary research into the areas where the respondents use the capbilities of GIS, other than those associated with applications solely for tourist purposes. Over $36 \%$ of participants declared that using a GIS proved useful in the decision-making process related to the purchase or rental of a property. Almost 34\% indicated that they used a GIS when choosing the venue for a conference, training, or seminar. The smallest number, $14.28 \%$, used GIS in the process of building a house, selecting company premises, or finding an apartment (Figure 11).

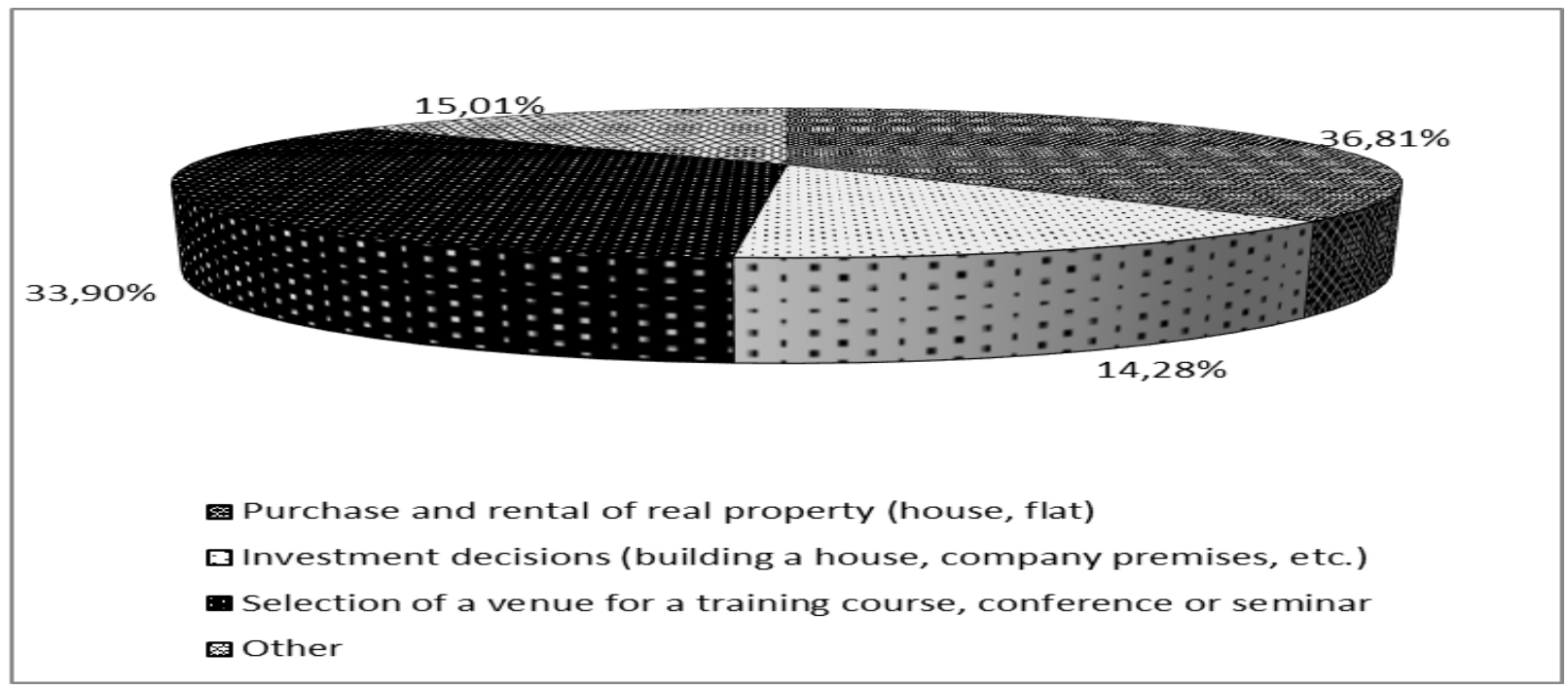

Figure 11. Using other functionalities of GIS

\section{Summary and conclusions}

The conducted research clearly indicates that GIS are useful in planning and taking individual trips (92\% of positive responses). This appears to be in contrast to the limited confidence with regard to such solutions while seeking information on a specific location. This particular issue, commented on briefly in this paper, should be considered in detail in subsequent stages of the research. During package tours, as the survey shows, the respondents rely on the experience of the travel agency which is responsible for organizing the trip. Business trips, on the other hand, are generally treated more as an initiative which contributes to gaining new qualifications rather than a tourist activity. Therefore, the events which accompany business trips or opportunities to visit the sites of the location or its surroundings seem to trigger less interest, and, as a consequence, only up to $50 \%$ of GIS users use the functionalities provided by the systems while travelling on business.

We noticed a marked difference between the users' approach towards GIS, depending on the kind of travel they embark on. In the case of organized, package tours, almost $62 \%$ of the participants were interested in the appearance of the facility, and $69 \%$ in the surroundings of the object. However, we should ask whether the remaining share of the study sample, $38 \%$ and $31 \% \%$ respectively, were not interested in the appearance of the facility, or had they used another source of information, other than the GIS? Taking into consideration the indicated need to use GIS from other sources (where over $40 \%$ would like to use the tourist information systems), the second option seems more probable. The question remains: why does GIS not meet 
this need to a higher degree since, as it appears, travelers with sufficient financial means at their disposal would gladly use the opportunity of making an informed decision taking into account the appearance or visible standard of the facility. Taking all the above into consideration, this appears to be an indication for the owners of hotels and other places providing various forms of active recreation, to take proper care of the appearance and the surroundings of their facilities. GIS may be used by tourists to check such parameters, and on this basis, they would make a choice with regard to the accommodation they would like to book.

The findings concerning the opinions on the use of GIS seem to present reverse relations. They are considerably less important than for example, the opinions of friends or the recommendations of anonymous travelers published on the Internet. This points to the limited trust placed in GIS. At present, we may only assume that the respondents perceive GIS as just another tool for marketing communication, presenting only positive aspects of the premises which are being viewed. We should take into consideration the need to carry out in-depth studies examining the reasons for such a situation to occur.

The response relating to the access to GIS during travel distinctly pointed to smartphone as the main device used by the study participants. The large share of smartphone users, 93\% of the respondents, came as no surprise considering vast popularity of the smartphone, especially among individuals. This information should be used as a recommendation to design responsive websites providing access to GIS. The indication concerning the popularity of smartphones as an access device is inconsistent with the responses in reagrds to sending information on geolocation. $76 \%$ of the study participants are not interested in using this functionality (responses: Sometimes or Not at all). Likewise, over $88 \%$ of the respondents either do not or seldom tag the visited places in GIS. We may assume that it stems from the travelers' wish to maintain their privacy.

More than 35\% of survey participants post videos and photos documenting their trips on social media to a large or moderate degree. We would expect a larger number of people to post photos or videos on the systems; however, those people who post the materials on the Internet provide valuable and sufficient information on the visited locations. Thanks to such users, it is possible to verify the reliability of the information available in GIS, e.g. check whether the photos posted on the website reflect the reality and are not outdated. Almost $42 \%$ of respondents visited virtual places which they saw during their trips. Most probably, the travelers wanted to check the information which is available in the Internet, and verify whether it is reliable.

At present, almost $81 \%$ of respondents declare the willingness to use GIS system again when planning their next trip. The users pointed to two main application areas, where we could change the amount of available information. We observe a marked difference (nearly 11\%) between the information which is provided and the information which is required by respondents in the case of ticket booking systems that allow users to purchase tickets for mass and individual, cultural events. The reverse relation is recorded in the case of the tourist information on the locations. Nearly $11 \%$ of respondents indicate the excess of the information on the premises. The survey participants indicate the information needs which are not properly covered by GIS. As we may notice based on the findings, accommodation/hotel booking systems are rather well integrated with GIS. This is indicated in the survey responses for over $60 \%$ of the participants, GIS are of large and moderate importance in the process of selecting accommodation. We should associate 
this fact with the long-term presence of such systems in the market and the possibility to personally verify the reliability of the services.

Interesting findings have been obtained with regard to the question concerning GIS applications for purposes other than those related to tourism. Over $70 \%$ of the respondents use the systems when purchasing real property or while selecting the venue for training or a conference. This indicates a significant role of GIS relevant to business applications.

Certainly, the changes in GIS applications will be visible, when the people born around 2000 whose natural habitat is the convergent and global Internet-based environment, enter the academic circles and the job market. We may expect changes in the approach to privacy or the decision-making processes supported with virtual assistants.

GIS are a rapidly developing field, which facilitates the design of applications managing and using geographic information, compatible with other media. In tourism, GIS play an important role in shaping the tourist companies' business strategies and GIS impact the travelers' decisions concerning tourism services. The systems are already used for such operations as a digital display of maps allowing to check the location of a facility; planning one's access route from any point on a map, using any means of transport; visualization of the appearance of the premises with a possibility to experience a virtual trip to its surroundings; and coordination of the undertaken activity analyzing the possibilities of booking transport, hotel services or planning cultural events. The future of GIS in tourism lies, as it appears, in further integration of the systems with applications allowing for free planning of private trips and making the stay more attractive for individuals (personalization), improving the availability of services associated with package tours, and contributing to the development of conference tourism. Cooperation with social media may lead to a specific transition of tourists (at least some of them) in more active prosumers.

According to the Gartner analytical company, even though at present only $23 \%$ of organizations use the systems, by 2020 we may expect a considerable increase in the number of companies, including tourist companies, which would incorporate the aspect of spatial data in their business activities, according to the assumed strategies of GLI (Geospatial and Location Intelligence). The main aim of using location information by the companies would be the potential of the rapidly developing electronic business sector, in particular an increasing number of mobile devices with Internet access, whose revenues in 2020 , according to analysts, would amount to $€ 25$ billion (gisplay.pl, 2015). This strategy would reduce the time needed to identify sites for the creation of new tourist facilities or find facilities to be rented by travel agencies or individuals as well as to plan the routes and interchanges of transport links in order to reduce the amount of time and money spent on commuting.

\section{References}

Aplikom (2015). Oprogramowanie Aplikom. Retrieved November 15, 2015 from http://www.aplikom.com.pl

ArcGIS (2015). ArcGIS - My maps. Retrieved November 14, 2015 from https://www.arcgis.com/home/webmap/viewer.html

AutoMapa (2015). Produkty, November 2015. Retrieved November 15, 2015 from 
http://www.automapa.pl/pl/produkty

Avdimiotis, S., Mavrodontis, T., Dermetzopoulos, \& A. S. Riavoglou, K. (2006). GIS applications as a tool for tourism planning and education: A case study of Chalkidiki, M. Tourism - An International Interdisciplinary Journal, 54 (4). 405-413.

Bahaire T., Elliott-White M. (1999). The application of geographical information systems (GIS) in sustainable tourism planning: A Review. Journal of Sustainable Tourism, 7 (2), 159174.

Boers, B., \& Cottrell, S. (2007). Sustainable tourism infrastructure planning: A GIS-supported approach, Retrieved November 09, 2015 from http://www.tandfonline.com/doi/pdf/10.1080/14616680601092824.

Brown G. \& Weber D. (2013). Using public participation GIS (PPGIS) on the Geoweb to monitor tourism development preferences. Journal of Sustainable Tourism, 21 (2). 192211. retrieved November 10, 2015 from http://www.tandfonline.com/doi/abs/10.1080/09669582.2012.693501.

Burrough, P. A. (1986). Principles of geographical information systems for land resources assessment. Oxford: Clarendon Press.

Caliper Corp. (2015). Maptitude GIS and mapping software. retrieved November 14, 2015 from http://www.caliper.com/maptovu.htm

Carver S. J. (1991) Integrating multi-criteria evaluation with geographical information systems. International Journal of Geographical Information Systems, 5 (3). 321-339, Retrieved November 21, 2015, from: http://www.tandfonline.com/doi/abs/10.1080/02693799108927858.

Chmielarz W. (2015). Study of smartphones usage from the customer's point of view. Procedia Computer Science, Elsevier, 65, 1085-1094.

Chmielarz W., \& K. Łuczak. (2015) Mobile banking in the opinion of users of banking applications in Poland. Applied Mechanics and Materials, 79 (5), 31-38.

Dueker, K.. J. (1979). Land resource information systems: A review of fifteen years' experience. Geo-Processing, 1(2), 105-128.

ESRI (2015). Esri software products, retrieved November 14, 2015 from http://www.esri.com/products.

Gaździcki, J. (1990). Systemy Informacji Przestrzennej. PPWK, Warsaw.

GEOPORTAL 2 (2015). Powiązanie z INSPIRE, retrieved November 15, 2015 from http://www.geoportal.gov.pl/o-geoportalu/powiazania-geoportalu/powiazanie-z-inspire.

gisplay.pl (2015). Analityka lokalizacyjna to przyszłość, retrieved December 02, 2015 from http://www.gisplay.pl/gis/5748-analityka-lokalizacyjna-to-przyszlosc.html.

Goodchild, M. F., Longley, P. A., Maguire D. J., \& Rhind D. W. (2006). GIS Teoria i praktyka, Warsaw, Wydawnictwo Naukowe PWN.

Google (2015). Device manager. Retrieved November 14, 2015 from https://www.google.com/android/devicemanager. 
Gotlib, D., Iwaniak, A. \& Olszewski R. (2008). GIS obszary zastosowań, PWN, Warsaw.

Harmon, J. E., \& Anderson, J. S. (2003). The design and implementation of geographic information systems. John Wiley and Sons Inc.: Hoboken, USA.

Instytut Meteorologii i Gospodarki Wodnej (2015). Retrieved November 15, 2015 from http://www.imgw.pl/.

Interia Mobtech (2014). Mobilne aplikacje w UE. 63 mld euro i 5 mln stanowisk do 2018 r (2014-02-23). Retrieved November 10, 2015 from http://mobtech.interia.pl/systemyoperacyjne/news-mobilne-aplikacje-w-ue-63-mld-euro-i-5-mln-stanowisk-do2018,nId,1110452.

Kraak, M. J. \& Ormeling, F. (1998). Kartografia - wizualizacja danych, Wydawnictwo PWN, Warsaw.

Obermeyer N. J., J. K. Pinto (2008). Managing geographic information systems, The Guilford Press, 2-nd Edition, New York, London,

Longley, P. A., Goodchild, M. F., Maguire, D. J. \& Rhind, D. W. (2015). Geografic Information Science and Systems. John Wiley and Sons Corp., NY.

Portal Geostatystyczny (2015). Przeglądarka Danych Geostatystycznych, retrieved November 10, 2015 from http://geo.stat.gov.pl/imap.

Poslad S, Laamanen, H., Malaka, R., Nick, A., Buckle, P., \& Zipf, A. (2015). Crumpet: Creation of user-friendly mobile services personalised for tourism. Retrieved December 12, 2015 from http://195.130.87.21:8080/dspace/bitstream/123456789/576/1/Crumpet creation of user-friendly mobile services personalised for tourism.pdf.

Regionalny Zarząd Gospodarki Wodnej w Krakowie (2015a). Wyznaczenie obszarów bezpośredniego zagrożenia powodzią w zlewni Sanu. Retrieved November 15, 2015 from http://oki.krakow.rzgw.gov.pl/Content/wwwdd/mapy_studia/san_orto.

Regionalny Zarząd Gospodarki Wodnej w Krakowie (2015b). Określenie zagrożenia powodziowego w zlewni Wisłoka. Retrieved November 15, 2015 from http://oki.krakow.rzgw.gov.pl/Content/wwwdd/mapy_studia/wislok_g.

Targeo (2015). Mapa cen. Retrieved November 14, 2015 from http://mapacen.targeo.pl.

Urząd m.st Warszawy (2012). O serwisie mapowym m.st. Warszawy (2012-07-12). Retrieved November 15, 2015 from http://architektura.um.Warsaw.pl/content/o-serwisiemapowym-mst-warszawy.

Urząd Miejski w Bytowie (2015). Zielona przygoda. Retrieved November 09, 2015 from http://bytow.com.pl/mapa.

WarszawskaStarowka.pl (2015). Retrieved November 15, 2015 from http://www.warszawskastarowka.pl.

Wikipedia (2015). John Snow. Retrieved November 14, 2015 from https://pl.wikipedia.org/wiki/John_Snow. 


\section{Authors' Biographies}

Witold Chmielarz, PhD - professor, head of Management Information Systems Department at Faculty of Management, Warsaw University. Specialist in Information Technologies, especially in website assessment and project management.

Oskar Szumski, PhD - researcher and lecturer at Faculty of Management of University of Warsaw. His main fields of interest are e-government systems and computer games application for management. 